\title{
OS ROLEZINHOS EM SHOPPING CENTERS: REFLEXÕES SOBRE O QUE AGREGAM E EM QUE DESAFIAM OS ESTUDOS DOS SHOPPINGS COMO ESPAÇOS DE SEGREGAÇÃO SOCIAL E URBANA
}

Juliana Cristina Teixeira ${ }^{1}$

Amon Narciso de Barros²

\section{Resumo}

O objetivo deste ensaio teórico é apresentar um breve panorama sobre o que os estudos que envolvem o espaço do shopping center (como os do campo da geografia urbana e os que estudam em geral as dinâmicas de segregação social nas cidades) já vinham discutindo a respeito de sua relação com o espaço urbano, com a segregação social, e com práticas culturais de consumo. Em seguida, como principal contribuição para a compreensão do fenômeno, refletir sobre o que os rolês agregam e em que desafiam os estudos sobre os shopping centers como espaços de segregação. Argumentamos que os rolês trazem novos elementos empíricos que reforçam a caracterização do shopping como espaço de segregação; e a caracterização dos espaços como estando envoltos por dinâmicas de significação, ressignificação e resistência.

Palavras-chave: Rolezinhos. Shopping centers. Espaços. Segregação social e urbana. Consumo.

\section{LOS ROLEZINHOS EN LOS CENTROS COMERCIALES: REFLEXIONES ACERCA DE LO QUE SE SUMAN Y EN LO QUE ELLOS DESAFÍAN LOS ESTUDIOS DE LOS CENTROS COMERCIALES COMO ESPACIOS DE SEGREGACIÓN SOCIAL Y URBANA}

\section{Resumen}

El objetivo de este ensayo teórico es presentar un breve panorama sobre el que los estudios que incluyeron el espacio del centro comercial (como el campo de la geografía urbana y el que estudian en general las dinámicas

\footnotetext{
${ }^{1}$ Doutora em Administração pela UFMG. Professora Adjunta do Departamento de Ciências Administrativas e Contábeis da Universidade Fedeal de São João del-Rei. E-mail: julianacteixeira@yahoo.com.br.

${ }^{2}$ Doutor em Administração pela UFMG. Professor da Fundação Getulio Vargas. E-mail: amon.barros@fgv.br

Revista Brasileira de Estudos Organizacionais · v. 3. n. 2, p. 101-126, dez.2016, eISSN: 2447-4851 Doi 10.21583/2447-4851.rbeo.2016.v3n2.80 Sociedade Brasileira de Estudos Organizacionais
} 
de la segregación social en las ciudades) ya estaban discutiendo acerca de su relación con el espacio urbano, con la segregación social y las prácticas de consumo cultural. Entonces, como una importante contribución a la comprensión del fenómeno, al reflexionar sobre cuáles son los papeles agregados y estudios desafiantes de centros comerciales como espacios de segregación. Argumentamos que los rolês traen nuevos elementos empíricos que refuerzan la caracterización del centro comercial como un espacio de la segregación; la caracterización de los espacios como estando rodeados de dinámicas de significación, resignificación y la resistencia.

Palabras clave: Rolezinhos. Centros comerciales. Espacios. La segregación social y urbana. Consumo.

\title{
THE ROLEZINHOS AT THE MALLS: REFLECTIONS ABOUT WHAT THEY ADD AND IN WHAT THEY CHALLENGE THE STUDIES OF THE MALLS AS URBAN AND SOCIAL SEGREGATION SPACES
}

\begin{abstract}
The objective of this theoretical essay is to present a brief overview about what the studies involving the mall space (like the field of the urban geography and the ones who study in general the dynamics of social segregation in cities) were already arguing about their relationship with the urban space, with the social segregation, and with cultural consumption practices. After that, as a major contribution to the understanding of the phenomenon, reflecting about what the rolês aggregate and in what they challenge the studies about the malls as segregation spaces. We argue that rolês bring new empirical elements that increase the characterization of the mall as a segregation space; the characterization of the spaces as being surrounded by dynamic of meaning, reframing and endurance.
\end{abstract}

Keywords: Rolezinhos. Malls. Spaces. Social and urban segregation. Consumption.

\section{Introdução}

Que perigo seria este do qual as pessoas se vêem protegidas ao desfrutar dos lazeres oferecidos pelos shopping centers? 'Provavelmente, o perigo que brota das desigualdades sociais estampadas na dinâmica da vida real, do 'mundo de fora' ao 

seus maiores atrativos' (PADILHA, 2008, p. 110).

Este ensaio teórico constitui um espaço de reflexão de pesquisadores que vinham lendo e estudando os shopping centers como espaços representativos de uma segregação socio-histórica na dinâmica simbólica das cidades, e que recentemente se depararam com fenômenos que se tornaram importantes alvos de discussão no Brasil no ano de 2013 e neste ano de 2014: os chamados "rolezinhos" de jovens em shopping centers.

Tratam-se de encontros realizados em shopping centers por jovens que residem sobretudo em bairros periféricos das cidades brasileiras. A disseminação da prática suscitou debates a respeito da segregação social e de práticas culturais e políticas de consumo. Registrou-se no país a ocorrência de rolês em cidades como São Paulo, Rio de Janeiro, Belo Horizonte e Porto Alegre, entre outras. Diante da discussão provocada por esses fenômenos, este artigo é um esforço de concatenação de ideias com o objetivo de lançar luz sobre um fenômeno tão recente, discutindo não só resultados de pesquisas já realizadas, mas refletindo e indicando desafios para novos estudos sobre os shoppings como fenômenos de segregação que devem considerar agora os rolês, entendidos aqui como manifestações mais explícitas de resistência à segregação representada pelo espaço dos shopping centers.

O objetivo do artigo é apresentar um breve panorama sobre o que os estudos que envolvem o espaço do shopping center (como os do campo da geografia urbana e os que estudam em geral as dinâmicas de segregação social nas cidades) já vinham discutindo a respeito de sua relação com o espaço urbano, com a segregação social, e com práticas culturais de consumo. Em seguida, como principal contribuição para a compreensão do fenômeno refletir sobre o que os rolês (1) agregam e em que (2) desafiam os estudos sobre os shopping centers como espaços de segregação.

O artigo é organizado em duas partes: a primeira traz uma discussão sobre os shoppings como fenômenos históricos de segregação social e urbana, apresentando brevemente o que os estudos já demonstravam a respeito desses espaços. Nessa primeira parte, vê-se os shoppings como fenômenos que são considerados "mecas" da mercadoria (ANDRADE, 2012) e espaços representativos de um consumo segregado. Além disso, são considerados fenômenos integrativos de deslocamentos históricos de centros urbanos tradicionais, como espaços inicialmente construídos para não pertencer a determinados grupos sociais, apresentando inclusive casos explícitos de discriminação em seu histórico. Ainda, discute-se como os estudos consideravam os shoppings como espaços que já se constituíam como lugares de resistência para jovens da 
periferia, que os frequentavam em busca de lazer e visibilidade, embora ainda não na proporção representada pelos rolês.

E é nessa relação do que os estudos já demonstravam com o fenômeno recente dos rolês que partimos para a segunda parte do estudo: a que traz reflexões a respeito do que agregam os rolês aos estudos do shopping center como espaço de segregação; e em que os desafiam. Dentre outras reflexões, trazem-se discussões a respeito do reforço que representam os rolês à caracterização do shopping como espaço de segregação; à intensificação do caráter dinâmico e simbólico de apropriação dos espaços (como significação, ressignificação e resistência); e reflexões de que o acesso ao consumo por parte de determinados grupos sociais não implica necessariamente na descontinuidade de outros processos de exclusão social.

O presente estudo contribui com a área de Estudos Organizacionais ao avançar nas discussões sobre o shopping center como organização com características peculiares e que são interpretados tanto a partir de uma concepção dominante - como espaços de distinção e de exclusão do outro periférico - como a partir de uma ideia divergente - como espaços a serem conquistados para que o periférico se aproxime do centro, se apropriando desse espaço.

\section{Os Shopping Centers como fenômenos históricos de segregação social e urbana: o que os estudos já demonstravam}

O que são, objetivamente, os shopping centers? São estabelecimentos fechados que se constituem como centros de consumo, agrupando diversas empresas de vendas e de prestação de serviços e possuindo uma administração geral que coordena o seu funcionamento (AGOSTINI, 2012). Por que os encontros de jovens da periferia particularmente em shopping centers? Não entrando ainda especificamente no mérito dessa questão, mas contribuindo para uma resposta à mesma, reforça-se que os shoppings são entendidos por estudiosos de dinâmicas espaciais urbanas simbólicas e de práticas culturais de consumo como símbolos de segregação, de não pertencimento a determinados grupos sociais, como os grupos de classes sociais inferiores aos quais justamente pertencem os jovens comumente vistos nos rolês.

Padilha (2006) afirmou em entrevista sobre os rolezinhos que os shoppings são "espaços de compra que segregam, impedindo a entrada de quem não tem poder aquisitivo ou de quem não se adequa ao ambiente dos shoppings - seja pelo modo de se vestir ou pelo modo de agir". Segundo a autora, os shoppings, assim como outros espaços privados, funcionam como espaços nos quais as classes de maior poder aquisitivo se 
protegem e se isolam da realidade - com sua desigualdade e violência urbana.

O primeiro shopping brasileiro (o Iguatemi, em São Paulo) foi criado em 1966.Mas o verdadeiro boom de construções de shoppings no país se deu na década de 80, sobretudo nas capitais e outros grandes centros urbanos da região Sudeste. Foi o início da reprodução, no país, dos modelos de malls norte-americanos (ALVES, 2011; ANDRADE, 2007; NASCIMENTO et al., 2013). Uma das características do modelo reproduzido no Brasil é a distribuição das lojas em âncoras e satélites. As lojas âncoras são aquelas com grande área bruta locável, geralmente localizadas nas extremidades dos pavimentos, visando estimular os sujeitos a circularem de uma ponta a outra do estabelecimento. As lojas satélite são usualmente distribuídas entre as lojas âncora e entre os acessos externos. São em geral lojas de locação, devido à necessidade da administração do shopping de resguardar a atualização do mix, estabelecendo um padrão comercial compatível com a sua proposta (ANDRADE, 2007).

O shopping se torna um lugar de idolatração à mercadoria. Sua construção se insere em uma dinâmica de organização do espaço urbano de acordo com a lógica do capital, é o "cenário onde o capitalismo protagoniza a acumulação de riqueza" (PADILHA, 2006, p. 46). No contexto capitalista, espaços urbanos específicos para o consumo precisam ser criados (ALVES, 2011). Além disso, o shopping se torna um espaço de lazer reificado (constituído como mercadoria), inserido em um contexto histórico de mercantilização da diversão. De acordo com Padilha (2006), o "shopping center nasce e se desenvolve como centro de consumo no seio da cidade capitalista de forma historicamente entrelaçada com a subordinação do lazer a essa lógica do capital" (Padilha, 2006, p. 46). Vê-se então nos shoppings uma aglomeração de mercadorias, mas o lazer nele também se torna mercadoria, como é o caso dos cinemas, dos parques, brinquedos, jogos eletrônicos, entre outros.

Padilha (2006, p. 45) associa as práticas culturais de consumo envolvidas nos shoppings centers com as "práticas da flânerie na Paris do século XIX". A autora considera que o surgimento do que hoje se conhece como shopping center está associado à construção das primeiras lojas de departamento européias, que estimulavam não só o consumo, como também a prática do flânerie: o gosto pelo simples andar pelas lojas para ver as vitrines. De acordo com ela, "o flâneur é aquele passante que busca uma identidade para si através do olhar" (PADILHA, 2006, p. 48).

A construção de espaços de passagens nos quais se vê vitrines reformula os espaços públicos, havendo um culto à exposição e à visibilidade (BENJAMIN, 2006). O início do costume de passear pelas galerias traz evidências do que hoje vemos com a privatização dos espaços 
urbanos (PAIM; BUENO, 2012). Com o crescimento da produção em massa, juntamente com a ampliação do número de trabalhadores assalariados, havia uma necessidade de organizar novas formas de distribuição, para facilitar o consumo e ampliar os mercados dos bens produzidos. O tradicional comércio das ruas não era suficiente para atender a esse objetivo. Era o período inicial do capitalismo urbano (PADILHA, 2006).

As ideias de Benjamin (2006), inclusive, permitem o estabelecimento de uma relação entre o processo de fetichização e a entrega à cultura do consumo como se fosse fonte de felicidade, processo esse que estimula até a compra de bens supérfluos. De acordo com Padilha (2006), constrói-se uma necessidade cultural de participar dessa fetichização para se integrar e ser feliz.

$\mathrm{Na}$ fetichização das mercadorias, estimulou-se o desejo pela novidade, o que favorecia a oferta de produtos diversificados e alimentava a formação dessa cultura de consumo. Houve também uma associação da aquisição de bens com a obtenção de status, o que favoreceu a valorização simbólica das mercadorias (PADILHA, 2006). O consumo se torna uma expressão da posição social que se ocupa (ANDRADE, 2012; NASCIMENTO et al., 2013).

Depois dessa fase inicial do capitalismo urbano na Europa, que ocorreu com destaque não só em Paris, mas também em Londres, houve nos Estados Unidos do período após a Segunda Guerra a proliferação de centros de consumo como os malls. E atualmente eles refletem hegemonicamente a cultura de consumo característica do contexto norte-americano (ANDRADE, 2007; PADILHA, 2006). Desde então, são espaços que integram um arsenal cultural para a constituição do consumo como um estilo de vida (NASCIMENTO et al., 2013). Para Padilha (2006), o shopping é um espaço de lazer reificado e potencializado pela publicidade, que exclui aqueles que não podem consumir, além de ignorar a cidadania, o espaço público, a cidade e sua história.

Em relação à cidade, enfatiza-se o processo de construção social do espaço urbano (VILLAÇA, 2011) de maneira segregada, entendendo a segregação como um processo social por meio do qual se estimula (ou garante) uma convivência entre os "iguais" (LEITÃO, 2005) e o afastamento dos socialmente "diferentes". Esse estímulo ou garantia diz respeito a construções sociais de hierarquias entre grupos por critérios como classe, raça e renda. Nesse sentido, segregação urbana e desigualdades sociais são dois fenômenos intrinsecamente relacionados (ANDRADE, 2002; NASCIMENTO et al., 2013; VILLAÇA, 2011).

Houve um processo de descentralização das cidades e a criação de novos mapas urbanos (ANDRADE, 2007). Antes mesmo da construção de shoppings no Brasil, já havia um fenômeno de segregação relacionado ao uso 
dos centros urbanos tradicionais, que passaram a ser mais frequentados por grupos socialmente desfavorecidos, enquanto os grupos simbolicamente poderosos (por aspectos como renda e influência social) se distanciavam em bairros mais valorizados e em condomínios fechados. Clubes foram tornados sofisticados para esses últimos grupos, mantendo a dinâmica de segregação para os momentos de lazer (ANDRADE; FONSECA, 2008).

Os centros tradicionais são também ocupados por negócios informais, como o comércio ambulante. Tornam-se também opção de moradia para quem não tem residência (DUHAU, 2001; ANDRADE, 2002). Todo esse processo contribui para um distanciamento entre os grupos sociais. O conceito de distância social se atrela ao de segregação, sendo que ambos dizem respeito tanto a aspectos espaciais como sociais (ANDRADE, 2002).

Para Andrade (2002, p. 5), “o homem metropolitano desenvolve a capacidade de sentir-se distante dos que estão próximos [como os vizinhos] como também de sentir-se próximo dos que estão distantes fisicamente [familiares, amigos, etc.]". Assim, é importante frisar que em um contexto urbano segregado, a delimitação espacial que aproxima os "iguais" não necessariamente os faz se sentirem próximos afetivamente. $\mathrm{O}$ que ocorre é a garantia de uma sensação de pertencimento a um grupo social em oposição direta ao não pertencimento a outro grupo considerado inferior (ANDRADE, 2002; NASCIMENTO et al., 2013).

Quando falamos em distância social, nos lembramos das considerações de Bourdieu (1996) de que os agentes e grupos são distribuídos de acordo com o seu capital global, que se compõe de diversos tipos de capitais e se estabelece enquanto princípio de diferenciação. Bourdieu (1987), por sua vez, considera que esses capitais se transformam em poderes sociais fundamentais, sendo o capital econômico, o social, o cultural e o capital simbólico, sendo estes últimos os capitais anteriores que são reconhecidos e legitimados. Para o autor, os elementos classificatórios dos agentes e dos grupos são o volume global de capital, a composição desse capital, e a evolução desse volume e dessa composição ao longo do tempo.

A partir desses elementos classificatórios os agentes e os grupos são posicionados no interior desse espaço, também de acordo com suas posições relativas em relação a outros grupos. Bourdieu (1996) reforça que quanto mais próximos os indivíduos ou grupos estão em relação à posse desses capitais, mais terão em comum. Para Bourdieu (1983, p. 82):

Às diferentes posições no espaço social correspondem estilos de vida, sistemas de desvios diferenciais que são a retradução simbólica de diferenças objetivamente inscritas nas condições de existência. As práticas e as propriedades constituem uma expressão sistemática das condições de existência (aquilo que 
Juliana Cristina Teixeira | Amon Narciso de Barros

chamamos estilo de vida) porque são o produto do mesmo operador prático, o habitus, sistema de disposições duráveis e transponíveis que exprime, sob a forma de preferências sistemáticas, as necessidades objetivas das quais ele é o produto $[\ldots]$.

Dessa forma, a segregação ocorrida nas cidades e em espaços como os shoppings, e a segregação relativa a diferentes práticas de consumo e lazer dos grupos no espaço urbano podem também ser compreendidas por meio dessa análise de Bourdieu (1983; 1996), que permite entender a existência de uma dinâmica simbólica de diferenciação dos grupos sociais.

Dentro de uma cidade então já segregada e já caracterizada por essa dinâmica simbólica, o shopping se torna mais um lócus de distinção. Boa parte dos shoppings se estabelece a partir de uma aura de segurança proporcionada pela sua constituição como um "espaço privado que aciona seus mecanismos de segurança de forma a impedir a [...] circulação de pessoas consideradas indesejadas" (PADILHA, 2006, p. 45).

\footnotetext{
Assim, o shopping center pode ser entendido como um espaço privado - que se propaga como público - criado para ser uma solução dos problemas da cidade onde reinam desajustes, desigualdades, contradições, imprevistos. Por isso, a cidade pode ser vista como o 'mundo de fora' em contraposição ao shopping center, o 'mundo de dentro'. O 'mundo de fora' é a 'realidade real', o espaço urbano e seu caráter público. Esse mundo contém uma outra realidade construída, o 'mundo de dentro', asséptico e isento dos fatores imprevisíveis que agem no 'mundo de fora' (Padilha, 2006, p. 45-46).
}

Essa dinâmica leva à constituição dos shoppings como espaços historicamente representativos da segregação social nas cidades. Historicamente porque o próprio processo de fetichização das mercadorias característico do início do capitalismo urbano na Europa, retratado aqui pelo surgimento das lojas de departamento em Paris e sua disseminação pela Europa,contribuiu para essa segregação.

Constrói-se no shopping uma espécie de cidade fictícia ou "artificial, que pretende substituir a cidade real e seus problemas" (PADILHA, 2008, p. 106). Benjamin (1985) já dizia em relação às galerias parisienses que suas passagens eram como cidades em miniatura. "A privatização dos espaços é trabalhada pelo olhar benjaminiano, mediante uma apurada observação da ilusão sutil de liberdade de circulação e de acesso às mercadorias que as galerias transmite ao comprador, longe do ruidoso e mau gosto do populacho" (PAIM; BUENO, 2012).

Atualmente os shoppings podem ser chamados de híbridos, pois se constituem centros de consumo amplificados e diversificados. Não propiciam somente a compra de produtos, mas o acesso a serviços e lazer. Mas são 
cidades mais fictícias ainda pela relação que estabelecem com a segregação e a oposição criada entre os citados "mundo de fora" e "mundo de dentro" (PADILHA, 2006; 2008). Como afirma Andrade (2007, p. 8), "a organização dos espaços é feita visando uma abstração total do mundo e do espaço exteriores a ponto de não sabermos se é dia ou noite lá fora, se chove ou se faz sol". É uma confinação de espaços públicos em espaços privados. Mesmo de uso coletivo, tornam-se espaços privados (ANDRADE, 2007; LEITÃO, 2005).

A sensação de segurança proporcionada pela constituição do shopping como uma cidade fictícia que nega os problemas da cidade "real" guarda relações com todo o "arsenal" de estratégias constituído para evitar que grupos sociais diferentes daqueles aos quais o shopping simbolicamente pertence frequentem seu espaço. No entanto, esse arsenal não é meramente simbólico, pois já produziu, antes mesmo dos rolês, relatos e casos de discriminações explícitas nos shoppings contra grupos como negros, pobres, homossexuais e transgêneros, inclusive proibições de entrada ou exclusões (AGOSTINI, 2012).

Além de manifestações explícitas como proibições ou exclusões, houve também a classificação simbólica e discursiva dos shoppings pelo tipo de público que os frequenta. Quando os jovens com as características dos que hoje são os integrantes dos rolês utilizavam os shoppings, já sofriam estereotipações e preconceitos por parte de seus frequentadores. Analisando discursos desses frequentadores sobre o perfil de público de shoppings da cidade de Belo Horizonte, Nascimento et al. (2013) observaram a descaracterização de shoppings como sendo "verdadeiros" shoppings por serem frequentados por jovens da periferia. Os autores analisaram discursos explícitos de associação simbólica do shopping frequentado por jovens pobres (e negros) ao espaço da favela.

Além disso, as próprias estratégias de organização e administração dos shoppings prevêem uma segmentação relacionada ao tipo de público e ao status simbólico do local (ou bairro) em que se encontram os shoppings. Como afirmam Nascimento et al. (2013),

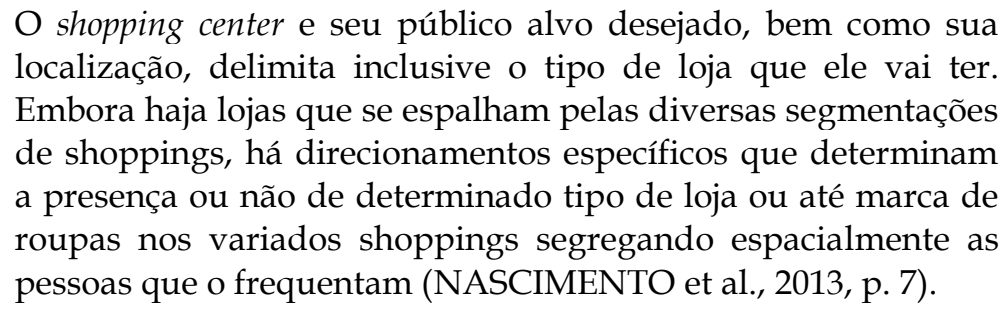

No caso do contexto brasileiro, além das dimensões classe, renda, e lugar de moradia (se os grupos residem em lugares simbolicamente considerados centro ou periferia), outra dimensão ganha importância quando se discutem os shoppings como espaços de segregação: a racial. Ela 
foi justamente associada aos shoppings por Nascimento et al. (2013), quando constataram que eles são espaços onde os negros não podem circular livremente sem que estereótipos negativos a eles socialmente vinculados sejam acionados, seja na percepção dos trabalhadores e seguranças dos shoppings, seja na percepção de quem os frequenta.

Quando falamos dos rolês, nos referimos a jovens cuja cor socialmente construída que lhes é associada é a cor negra. Além disso, em contextos latino-americanos marcados pelo colonialismo, os shoppings são considerados figuras paradigmáticas do discurso colonial, dizendo respeito a relações de poder e racismo (ANDRADE, 2012). Observa-se a

[...] construção do shopping como uma 'área dura' específica em
que a 'cor' afeta a permissão simbólica para determinados
grupos sociais e [...] espaços simbólicos [...] em que a
personagem do jovem negro, mano, favelado e que gosta de
funk é implicitamente negada como personagem comum a um
shopping. Por esse motivo, ir com a cor negra (entendendo a cor
como uma construção social e não meramente a cor da pele) a
um shopping pode assumir basicamente dois sentidos [...]: (1) ser
favelado, mano e 'sou phoda' e (2) significa frequentar aquilo
que simbolicamente deixou de ser um shopping (NASCIMENTO
et al., 2013, p. 14).

Em relação às cidades "reais", a construção dos shoppings provocou uma intensificação de três aspectos já discutidos: a constituição segregada do espaço urbano; a segregação atrelada aos momentos de lazer; e os deslocamentos dos centros urbanos tradicionais, com a criação de novos centros e o abandono, pela classe média, de outros (ALVES, 2011; NASCIMENTO et al., 2013). De monocêntricas, as cidades passaram a ser policêntricas (ALVES, 2011).

Sobre os shoppings, Leitão (2005) considera que eles só perdem para os condomínios fechados como símbolos contemporâneos de segregação urbana, consideração essa que não nos faz reagir com espanto ao fenômeno dos rolês. Até porque os jovens da periferia já frequentavam os shoppings, embora não em grandes grupos ou não na proporção que vemos agora.

Moura (2012) estudou a utilização dos shoppings como espaços de sociabilidade por parte dos jovens da periferia da cidade de Salvador. Ressalta que, mesmo fazendo parte de grupos sociais que sofrem certo constrangimento dentro desses espaços, esses jovens têm nesses lugares um de seus espaços favoritos de lazer, identificam-se com a "pequena cidade" ali construída e gostam de "curtir a vida" nessa "cidade" (MOURA, 2012, p. 6).

Após apresentado brevemente um panorama sobre o que têm discutido os estudos dos shoppings como espaços de segregação, partimos 
para o principal propósito deste ensaio: pensar o que os rolezinhos agregam e em que desafiam os estudos neste campo de pesquisa.

\section{$O$ que os rolezinhos agregam e em que desafiam os estudos dos shoppings como espaços de segregação social e urbana}

Assumindo a limitação de estar falando sobre um fenômeno muito recente e que tem seus desdobramentos ainda não definidos, parte-se nesta segunda parte para uma resposta à questão colocada na Introdução: o que os fenômenos dos rolês (1) agregam e em que (2) desafiam os estudos sobre os shopping centers como espaços de segregação?

\section{(1) O que o fenômeno agrega?}

Para essa questão, ressaltamos quatro aspectos. (a) Os rolês trazem novos elementos empíricos que reforçam a caracterização do shopping como espaço de segregação. (b) Os rolês trazem novos elementos empíricos também para a caracterização dos espaços como estando envoltos e sendo construídos por dinâmicas de significação, ressignificação e resistência no que se refere às suas possibilidades de uso e de apropriação. Nesse sentido, consideramos que os rolês trazem manifestações mais explícitas de resistência ao shopping como espaço de segregação. (c) Outro aspecto importante é que o fenômeno reforça algo que alguns estudos já apontavam: o acesso ao consumo por parte de determinados grupos sociais não implica necessariamente a descontinuidade de outros processos de exclusão social. (d) O último aspecto é que o fenômeno demanda interfaces entre vários campos de estudo para ser compreendido, o que traz novas possibilidades para as pesquisas.

Sobre o primeiro aspecto, (a) os rolês e seus desdobramentos trazem novos elementos empíricos que contribuem para o pensamento do shopping center como espaço de segregação. Eles desafiam uma ordem até então estabelecida: a constituição simbólica de um "espaço em que, prioritariamente, circulam pessoas iguais. [Por isso, a] estranha presença de um outro, um 'intruso', é rapidamente percebida por pessoas e por câmeras." (PADILHA, 2008, p. 115). A forte repressão aos rolês representam justamente essa tentativa de restabelecer a ordem que faz parte de um shopping center idealizado para contar com essa assepsia social.

Rompe-se com a caracterização dos shoppings como lugares que atraem apenas pessoas que se identificam de alguma forma (PADILHA, 2006). Mais tribos se formam nesses espaços. Esses jovens da periferia podem trazer um sentimento de identificação dentro de seu grupo, mas 
essa identificação não é mútua em relação aos grupos que simbolicamente pertencem aos shoppings. Não se trata mais agora de um grupo relativamente homogêneo frequentando o shopping center.

A reação negativa diante dos rolês por parte dos shoppings, do poder público, do judiciário e da sociedade de uma maneira geral demonstra uma tentativa de proteger a possibilidade de ir aos shoppings fugindo dos aspectos negativos das cidades, pois a "qualidade de vida" propiciada pelo espaço do shopping passa a ser ameaçada (PADILHA, 2006). E essa reação só reforça a dimensão segregatória presente nesse espaço. Se ela não estivesse presente, os rolês não seriam vistos com tamanha curiosidade, estranhamento e rejeição. Pois rompem com a característica idealizada do shopping como sendo um lugar inserido, mas afastado do espaço urbano, onde o imprevisível não acontece. "O que prevalece é a vontade da posse, da distinção ou da participação em um grupo social privilegiado e, com isso, do poder individual - ainda que ilusório" (PADILHA, 2006, p. 56).

O segundo aspecto importante é que (b) os rolês trazem novos elementos empíricos que reforçam que os espaços sociais contam com práticas e dinâmicas de significação, ressignificação e resistência. A significação do shopping center seria sua idealização como esse espaço asséptico, distante de problemas e onde se pode realizar desejos e sonhos. As ressignificações são as diversas maneiras pelas quais os indivíduos podem se apropriar desse espaço. Embora constituídos e significados de determinada maneira, podem ser utilizados e apropriados de diferentes formas. Os grupos sociais podem se apropriar desses espaços para finalidades distintas ou para estabelecer diferentes relações identitárias com os mesmos.

A própria utilização dos shoppings pelos jovens da periferia representa uma forma possível de ressignificação, pois essa forma de uso não faz parte de sua significação idealizada. E essa ressignificação ganha contornos de resistência - entendida aqui em um sentido foucaultiano (FOUCAULT, 1992), o que considera que onde há poder, há resistência, sendo essas duas dimensões relacionais - a partir do momento em que esses jovens utilizam um espaço que não foi para eles idealizado.

Nesse sentido, consideramos que os rolês representam manifestações mais explícitas de resistência às significações hegemonicamente estabelecidas para os shoppings. Para os estudos que já vinham sendo realizados a respeito dos shoppings como espaços de segregação, os rolês agregam a possibilidade de se observar um fenômeno que simboliza de maneira mais contundente essa resistência. Padilha afirma, em relação aos rolês, que 
Juliana Cristina Teixeira | Amon Narciso de Barros

Os shoppings são símbolos de uma sociedade de consumo e de abundância de bens materiais. São símbolos da lógica do 'compro, logo existo'. Forçar o acesso a esses espaços - que a periferia sabe que não lhe pertence - é um ato simbólico para dizer: 'quando a gente vem aqui a gente incomoda os burguesinhos que historicamente nos desprezam'. Uma longa história de invisibilidade vivida pelos pobres no Brasil está vindo à tona com essas 'invasões' dos shoppings centers. [...] Esses movimentos chamados de 'rolezinhos' são [...] uma tentativa de furar a barreira da invisibilidade a que esses jovens pobres estão sujeitos (POLETTO, 2014, p. 01.).

Voltando à perspectiva de Foucault (1992) que considera poder e resistência duas dimensões relacionais, e que todos os sujeitos estão em condições tanto de exercer o poder quanto de sofrer a sua ação, além da resistência, os rolês mostram o poder que os jovens da periferia podem também exercer sobre os espaços e a sociedade: um poder que tem como efeito o incômodo. Como se ressaltaou anteriormente, esses jovens já frequentavam os shoppings. Sua presença nesses espaços já era metaforicamente considerada "invasão dos morros aos shoppings centers" (NASCIMENTO et al., 2013). No entanto, nada em uma dimensão como a que estamos presenciando agora com os rolês.

O terceiro aspecto importante é que (c) os rolês agregam elementos para a consideração de que o acesso ao consumo não implica necessariamente a descontinuidade de outras dimensões da exclusão social. Mesmo que esses grupos da periferia já frequentem esses espaços, continuam sendo vistos como grupos a eles não pertencentes. E seu acesso a esses lugares, como visto em outro ponto, leva inclusive à descaracterização simbólica de um shopping como sendo um "verdadeiro shopping" (NASCIMENTO et al., 2013). Assim, o problema não é meramente econômico, mas também social.

$\mathrm{O}$ último aspecto que se ressalta em relação ao que agregam os rolês ao estudo dos shoppings é que (d) eles constituem fenômenos que demandam interfaces com vários campos de conhecimento para serem compreendidos. Faz-se necessário e se abrem possibilidades para o estudo desses fenômenos de maneira associada, por exemplo, ao estudo de práticas socio-espaciais; práticas culturais e políticas de consumo; o estudo do comportamento de jovens (e particularmente de jovens da periferia); da segregação urbana em uma dimensão mais ampla e não somente relacionada ao espaço estrito do shopping center; das práticas de contenção ou repressão aos rolês por parte dos administradores dos shoppings e dos agentes públicos; de políticas públicas que impactem nas práticas de lazer e nas dinâmicas de segregação urbana; de comportamentos de consumo; do aumento do poder de compra de determinados grupos sociais, entre 
outras possibilidades. Todas essas interfaces se tornam agendas de pesquisa a serem exploradas.

Para essas várias necessidades e possibilidades, diversos campos de conhecimento podem ser acionados: sociologia, antropologia, filosofia, psicologia, geografia urbana, geografia da mobilidade, arquitetura e urbanismo, entre outros.

\section{(2) Que desafios o fenômeno dos rolês traz para o estudo dos shoppings como espaços de segregação?}

Para essa questão, são pontuados dois aspectos: (a) a necessidade de entender de maneira mais aprofundada qual é a relação estabelecida entre os rolês e a dimensão do consumo, dimensão essa que foi brevemente discutida na primeira parte deste ensaio; e (b) algo que se acredita ser um desafio relativo à posição do pesquisador diante do fenômeno que estuda - a tendência a se considerar (assim como o fazemos aqui) o rolê como uma prática política, enquanto se observa que essa dimensão política não é necessariamente reconhecida pelos próprios jovens que participam dos rolês.

Sobre o primeiro aspecto, (a) o consumo tem sido uma dimensão bastante apontada nas discussões sobre os rolês. No entanto, em relação a essa dimensão, pontua-se o desafio de analisar de maneira mais aprofundada qual é sua relação específica com o fenômeno dos rolês.

Para dar conta deste desafio, considera-se que a dimensão do consumo está intrinsecamente relacionada ao fenômeno dos rolês. No entanto, não se sabe ainda se esse é o aspecto central para a compreensão do fenômeno, que não deve ser pensado de maneira isolada para justificar os rolês ou para justificar o porquê agora os jovens se aventuram "em bando" nos espaços dos shoppings. Como se, em um "click", pelo recente aumento do poder de compra de determinados grupos sociais, tivessem resolvido ir então aos shopping centers.

Como já afirmamos, os shoppings já são frequentados há tempos por esses jovens e, apesar de não serem lugares simbólicos para eles, gostam de "curtir" nesses espaços. Moura (2012) já inclusive destacou esse aspecto uma postura desses jovens que pode ser metaforicamente associada à expressão: "no shopping nóis é patrão". Já se associava a eles uma postura "marrenta" nesses espaços (NASCIMENTO et al., 2013, p. ???).

Além disso, o outro risco é pensar que somente agora esses jovens consomem especialmente marcas simbolicamente valorizadas. Como se apenas agora, por meio de evidências como o crescimento do chamado funk ostentação, eles tivessem se aberto para o consumo. Nesse sentido, ao pontuar a relação entre o rolê e o consumo, ressaltamos a importância de pensar esse aspecto de maneira profunda e historicizada. 
As marcas são sinais de distinção simbólica há alguns anos não só para os grupos sociais favorecidos, mas também para os grupos da periferia (CASTILHOS, 2007; SCALCO; PINHEIRO-MACHADO, 2010). Algumas marcas apontadas como preferidas por esses jovens já têm uma posição consolidada entre esses consumidores. Nesse sentido, cabe destacar a importância de se analisar o que os estudos sobre práticas de consumo de grupos populares ou de baixa renda apontam, para não se cair no risco de pensar que só agora, com o que se convenciona chamar de ascensão da classe $C$ no país, esses jovens despertaram para o consumo, e especificamente para o consumo de marcas que encontramos nos shoppings.

É errôneo entender que a valorização do consumo, a busca da visibilidade por meio dos produtos consumidos, ou que a busca pela visibilidade nos shoppings seja algo exclusivo dos jovens que agora se aventuram nesse espaço e que se identificam simbolicamente como grupo pelas marcas que vestem, por exemplo.

Acredita-se que a segregação deva ser pensada de maneira vinculada às discussões que associam os rolês à dimensão do consumo. Por que as práticas de consumo e as práticas sociais desses jovens ganham destaque agora? Justamente por eles terem visibilidade em um espaço que não lhes era simbolicamente pertencente, o que não significa que já não estavam antes associados à dimensão simbólica e onírica do consumo. $\mathrm{O}$ que não significa também que essa espetacularização do consumo seja a eles exclusiva ou tenha deles se originado, como pudemos perceber quando discutimos a valorização do consumo como prática envolvida no início do capitalismo urbano na Europa.

No final do século XIX no Ocidente, a cultura de consumo já começava a se instalar (PADILHA, 2006). A busca pelo prazer de compra já começava a ultrapassar a busca pela compra baseada no critério de utilidade dos bens. O que muda agora é o grupo social que está sendo alvo da discussão sobre a cultura de consumo por meio dos debates sobre os rolês. Há algum tempo já se fala também em um conceito diferenciado de shopping, pelo menos em relação à finalidade tradicional para a qual foi criado. Andrade (2007) fala de um novo conceito de shopping que quebra "o paradigma de que fazer compras em shopping é caro" (ANDRADE, 2007, p. 117). Para o autor, esses shoppings buscam alguns lojistas menores e não grandes grifes.

Outro aspecto importante que leva a necessidade de se ter cuidado ao associar os rolês com a dimensão do consumo é que os shoppings, mesmo antes de serem frequentados em grandes grupos pelos jovens da periferia, eram considerados símbolos da espetacularização (GREGOLIN, 2003) do consumo. Ou seja, essa espetacularização não é um fenômeno novo relacionado a esses jovens, já era relacionado aos grupos sociais de 
pertencimento simbólico aos shoppings. É como se esses jovens estivessem reproduzindo práticas dos grupos sociais privilegiados que lhes eram restritas ou dificultadas, reproduzindo valores de uma sociedade de consumo.

Por isso, perguntar, como se tem feito nas redes sociais, o porquê deles não fazerem rolês em bibliotecas ao invés de fazerem nos shoppings é implicitamente desconsiderar que os jovens de grupos sociais favorecidos frequentaram desde sempre os shoppings, e não somente ou necessariamente bibliotecas. Além disso, os shoppings já eram considerados lugares nos quais "o sujeito pode ver e ser visto" (ANDRADE, 2007, p. 120).

Em nossa opinião, esse primeiro desafio discutido aqui está acompanhado de outro: um desconhecimento muito grande a respeito das práticas de grupos que, mesmo sendo maioria em termos quantitativos, são simbolicamente constituídos como "os outros". Sobre esse aspecto, a revista Veja fez uma reportagem de capa apontando a existência de "outro" Brasil que, mesmo maioria, é desconhecido: aquele constituído pelas periferias. Na reportagem, a periferia é metaforicamente considerada um "país dentro do Brasil com 155 milhões de habitantes" (VEJA, 2014a, p. 1), ou seja, uma maioria constituída como "o outro". A manchete de capa traz os dizeres: "só você não me conhece" (VEJA, 2014a, p. 1).

Em um tom crítico, a periferia é tratada como "um Brasil que costuma ser lembrado apenas pelos problemas que cria, os 'rolezinhos' nos shopping centers, ou nos quais muitos de seus habitantes vivem imersos, chacinas, enchentes e endemias" (VEJA, 2014b, p. 13). Relativamente ao aspecto do consumo, antes mesmo dos rolês acontecerem, essa periferia, se fosse isolada como um país, teria, de acordo com o Instituto Data Popular, um poder de compra que a colocaria "no G20 do consumo mundial, ocupando a $16^{\mathrm{a}}$ posição no ranking de países que mais gastam [...]. Como mercado consumidor, portanto, as periferias brasileiras têm mais poder de compra do que a Suíça, a Holanda ou a Turquia" (VEJA, 2014b, p. 13).

Feitas então essas ressalvas sobre cuidados necessários ao se relacionar os rolês ao consumo, não se deixará de tecer aqui algumas relações importantes do fenômeno com essa dimensão (sempre de maneira associada à lógica da segregação e/ou da distinção simbólica entre grupos sociais), sem deixar de ressaltar mais uma vez que essas relações ainda precisam ser teórica e empiricamente aprofundadas.

O consumo de produtos pode ser considerado uma ação a partir da qual se estabelecem e se reafirmam distinções entre os diferentes grupos sociais. Todos consomem algo e a forma como essa ação se dá é um aspecto que pode reforçar a posição da elite, estabelecendo uma hierarquia que coloca sua maneira de consumir como superior à de outros grupos. Mesmo os que negam explicitar sua identidade a partir dos objetos que 
consomem, afirmam dessa maneira um aspecto de diferenciação de outros grupos sociais. O consumo de produtos, bem como o espaço onde ele ocorre, é uma ação que não acontece descolada dos contextos de contraposição entre grupos, mas se estabelece a partir dessas diferenças construídas no campo dos símbolos, como é possível notar a partir de Nascimento et al. (2013).

Neste texto, presume-se que dada a impulsão por se diferenciarem uns dos outros, a apropriação de certos objetos ou espaços por grupos "subalternos" impele as camadas superiores a novos gostos para permanecerem distintas. Se dado produto ou, no caso, espaço perde sua raridade e passa a ser acessível a ocupantes de grupos sociais com menor poder aquisitivo, torna-se necessária a migração para outros espaços a fim de manter essa ação como capaz de reiterar aspectos distintivos. Interessante que Renato Meireles, diretor do Instituto Data Popular, afirmou que algumas empresas vêm procurando o Instituto para desassociar suas marcas do consumidor da periferia (NEUMAN, 2014). Nessa dinâmica é interessante notar que as camadas mais abastadas não perdem nada real, apenas a exclusividade de uso do espaço e dos bens (o que, simbolicamente, pode significar perder tudo). Conforme Bourdieu (1996, p. 27, grifos nossos): “a posição ocupada no espaço social, isto é, na estrutura de distribuição de diferentes tipos de capital, [...] comanda as representações desse espaço e as tomadas de posição nas lutas para conservá-lo ou transformá-lo".

Para Bourdieu (1983), os grupos sociais reforçam a todo momento, nas ações de seus indivíduos, tanto o chamado à conformidade ao padrão do grupo quanto o alerta para que não se enfraqueçam os laços de pertencimento ao se assumir comportamentos associados a outras camadas da sociedade. Ao mesmo tempo, o consumo é um espaço no qual a distinção pode se fazer mais clara, pois nem todos consomem da mesma forma. O consumo é objeto de uma estilização que cria hierarquias no campo simbólico.

Interessante notar que Bourdieu (1983) ressalta o gosto pela discrição e a valorização dos "modos", que fundamentaram parte das críticas à realização dos rolezinhos. Estes aspectos são, para o autor, aspectos profundamente arraigados do habitus burguês em contraposição às pessoas mais pobres (à pequena burguesia, nas palavras de Bourdieu). Ao se apropriarem de um espaço que não é designado como seu e a partir de ações que se contrapõem àquelas efetuadas pelas classes mais abastadas, os jovens das periferias atrapalham a busca pela "originalidade" do grupo que tem o seu espaço ocupado (ou, talvez na visão do grupo, "invadido").

Numa analogia ao que Bourdieu (2007) aponta em relação às galerias de arte, ao adentrar em um shopping center que não havia sido 
designado para seu uso, os jovens das periferias vão também contra as expectativas de ocupação e uso daquele espaço apenas por um determinado grupo social, ao qual não pertencem.

Há aqui outro elemento que merece ser notado que coloca frente a frente a identidade que as classes dominantes atribuem ao conjunto das classes dominadas versus a autorrepresentação desses grupos, no caso como pessoas aptas a participar dos espaços de consumo. Isso é tanto mais interessante porque para Bourdieu (2007) as ações dos agentes no mundo social são fruto da incorporação de estruturas objetivas que tendem a ser reproduzidas e naturalizadas, ao mesmo tempo em que devem ser bem demarcadas e reiteradas para que se sustentem sua reprodução.

$\mathrm{O}$ ato de comprar em shoppings, em certa medida, se assemelha ao passeio por uma galeria nas quais há obras de arte em exposição. Excluídos os aspectos funcionais da experiência de comprar, a ida ao shopping center como passeio despretensioso requer o tempo livre que, muitas vezes, as classes mais abastadas reconhecem como um privilégio seu. Dessa forma, a utilização do tempo para ir ao shopping fazer um rolê atrai reiteradas vezes o comentário sarcástico: por que não na biblioteca (ao que se pode acrescentar: para que vocês façam algo de útil com o tempo de vocês)? No momento em que as camadas de menor poder aquisitivo se apropriam de aspectos do ato e do espaço de consumir que são explicitamente direcionados à burguesia e passam a fazer do consumo uma forma de "estilização da vida" (BOURDIEU, 1983), com produtos que as camadas médias e abastadas reconhecem como "seus", eles afrontam a capacidade de distinção desses grupos.

Como aponta Bourdieu (1983), a possibilidade de estilizar a vida está ligada à própria possibilidade de se realizar o desperdício ostentatório, em contraposição ao restrito atendimento às demandas cotidianas, que se fazem sentir de forma mais restritiva sobre aqueles que têm menos tempo livre e menos recursos materiais.

Ainda seguindo os apontamentos de Bourdieu (1983), deve-se ressaltar que a fruição do membro das classes mais abastadas (o "burguês") se dá em geral a partir da apreciação comedida, pouco expansiva, da experiência silenciosa e introspectiva. Ora, embora não se tenha realizado uma pesquisa específica não é difícil associar essas características ao passeio no shopping silencioso, com suas vitrines coloridas, convidando à apreciação e com um espaço específico para a conversa e quaisquer fruições (a praça de alimentação). Enquanto isso, por outro lado, o rolezinho se estabelece exatamente como o oposto dessa experiência, uma vez que é a franca diversão espalhafatosa que se efetivou nesses encontros, com música, alegria escancarada e, ainda, algum apelo ao flerte e à sensualidade. Além disso, ao transcorrerem em espaços que não lhes foram designados, os praticantes dos rolês simbolizam o não 


\section{OS ROLEZINHOS EM SHOPPING CENTERS: REFLEXÕES SOBRE O QUE AGREGAM E EM \\ QUE DESAFIAM OS ESTUDOS DOS SHOPPINGS COMO ESPAÇOS DE SEGREGAÇÃO SOCIAL E URBANA \\ Juliana Cristina Teixeira | Amon Narciso de Barros}

reconhecimento dos espaços delimitados a priori, o que é um ato que tem conotações políticas, ainda que não intentadas.

Contudo, não quer dizer que os jovens que fazem parte dos rolês se apropriam dos espaços e dos produtos símbolos das camadas mais abastadas da mesma forma que elas. Há, certamente, uma ressignificação dos significados que, entretanto, parecem derivar daqueles atribuídos por essas mesmas camadas superiores. Em outras palavras: os espaços e os produtos escolhidos mimetizam as escolhas das classes mais abastadas, embora adquiram novo sentido uma vez que, em si mesmos, não são capazes de mudar os aspectos componentes do habitus. As classes populares realizam, assim, uma estilização ainda que involuntária dos gostos da burguesia.

O segundo desafio que se discute é a (b) tendência a se caracterizar o rolê como prática política, ou com efeitos políticos, enquanto a maioria desses jovens não reconhecem essa dimensão política de seus próprios atos. Este desafio se refere à posição do pesquisador diante do fenômeno ou dos sujeitos que estuda.

Sobre esse aspecto, argumentamos que, ainda que as ações dos jovens da periferia possam não ser ações conscientes de afronta ao sistema - suposição reiteradamente veiculada por diversos veículos de comunicação que realizaram entrevistas com os participantes que destacam que só querem ir para se conhecer, se encontrar, se divertir e namorar - ela produz efeitos políticos. Isso porque a atual configuração da sociedade brasileira não "permite" que os espaços de consumo sejam para todos. Ao reivindicá-los, ainda que por alguns momentos, os jovens da periferia confrontam estruturas sociais já estabelecidas.

Uma experiência ocorrida em 2000 no Shopping Rio Sul, zona sul do Rio de Janeiro, é um exemplo interessante nesse desafio de distinguir entre práticas que possuem um caráter deliberadamente político e as que apenas produzem efeitos políticos. Essa experiência trazia um sentido explicitamente político por parte dos sujeitos participantes, o que faz com que ela difira dos rolezinhos.

Em agosto de 2000 cerca de 150 moradores de favelas, desempregados e trabalhadores sem-teto organizados escolheram o Shopping Rio Sul [...] como local de um protesto contra a desigualdade social. $\mathrm{O}$ evento, até então inédito, chocou frequentadores habituais e muitos lojistas que fecharam as suas portas com medo de assaltos e saques. Um dos organizadores do manifesto [...] declarou à imprensa que tinham a intenção de 'incomodar' e de 'trazer um pouco de realidade para o centro do consumo'. Com isso, pretendiam mostrar que, enquanto algumas pessoas privilegiadas consomem e desfrutam de seu 'tempo livre' com segurança em lugares limpos, modernos e atraentes, existem milhares de

Revista Brasileira de Estudos Organizacionais · v. 3. n. 2, p. 101-126, dez.2016, eISSN: 2447-4851 Doi 10.21583/2447-4851.rbeo.2016.v3n2.80

Sociedade Brasileira de Estudos Organizacionais 
No caso dos jovens da periferia nos rolês, cabe ressaltar que é esperado que eles neguem um sentido deliberado de ato político às suas ações porque estão acionando os shoppings como lugares de encontros e de entretenimento (ANDRADE, 2007). Assim como outras pessoas que frequentam os shoppings, "levam em si um desejo subjetivo de tribalizarem-se, de praticar com o seu grupo aquele ritual de estar junto" (Andrade, 2007, p. 46). O que, de certa maneira, explica a continuidade de alguns rolês em outros espaços como praças como forma de fugir da significativa repressão enfrentada nos shoppings.

No caso do shopping, Andrade (2007) afirma que várias territorialidades simbólicas são construídas em seu espaço. O território seria a representação da manifestação de poder e de delimitação espacial; e territorialidade, por sua vez, seria a qualidade de ser território. Em um sentido simbólico, a territorialidade diz respeito a relações de poder que "promovem a distinção e/ou a criação de identidades entre os Sujeitos de modo a torná-los capazes de demarcarem entre si áreas de influência, oscilante em seus limites" (Andrade, 2007, p. 43). Para a autora, tribos se formam nos shoppings, como as tribos objetivadas (ou subjetivadas) por meio dos rolês.

Ainda de acordo com a autora, a tendência é que as pessoas que vão aos shoppings sigam um comportamento "comme il faut" (de acordo com os costumes, decoroso, decente). Mas algumas tribos, segundo ela, acabam se colocando no papel de apresentar um comportamento diversificado, como é o caso dos jovens da periferia que aqui focalizamos.

\footnotetext{
Estes jovens reúnem-se [...] para serem vistos e terem assim, em parte, realizados os seus sonhos de visibilidade. No processo de estarem ali para ver e ser vistos eles passam a ser transeuntes de um entre-lugar, que é aquele no qual eles se reúnem e que é marcado pelo apego dos Sujeitos Tribais em relação ao Lugar. Para estes Sujeitos aquele lugar (shopping) só existe porque existem outros Sujeitos que, como eles próprios, estão ali para shoppinizarem-se, buscando seu Lugar nesta sociedade (ANDRADE, 2007, p. 117).
}

Essas considerações ajudam a entender porque esses atos são feitos em grupo, ou em "bandos" como pejorativamente se pode dizer. Além disso, o comentado desejo pela "tribalização" (p. ???) e pela visibilidade ajuda a trazer algum elemento de compreensão a respeito do porquê há a negação explícita do sentido político do rolê por parte de seus próprios praticantes: eles podem estar querendo "só se divertir". No entanto, o 
desafio dos pesquisadores é justamente refletir os efeitos políticos causados por essa "diversão".

Uma ressalva importante a essas considerações, porém, é que reconhecer a existência de discursos que alegam a mera diversão por parte desses jovens implica em um risco de se acreditar que, para eles, tanto faz estar em shoppings ou em praças públicas, desde que estejam com o seu grupo. Não se coaduna com esse ponto de vista porque se acredita que ir ao shopping centers, para esses jovens, é uma possibilidade muito maior de visibilidade e de "causar", de resistir, ainda que possam não reconhecer a dimensão dessa resistência.

Ir ao shopping representa uma afirmação implícita e simbólica de que esse lugar também deve ser deles. Trata-se de uma resistência que, ainda que não seja deliberada, norteia implicitamente suas ações. Eles percebem o quanto incomodam e podem causar medo nesses espaços. Neste ensaio, visualizam-se suas ações como um ato de resistência, entre outros aspectos, ao shopping como espaço de segregação e a uma exclusão da esfera do consumo pela sociedade capitalista.

É comum que as praças públicas, já sob os efeitos dos deslocamentos dos centros urbanos, sejam já lugares de pertencimento simbólico aos jovens da periferia uma vez que, no processo de segregação urbana, algumas acabaram se tornando lugares mais frequentados por grupos de classes sociais inferiores (ANDRADE; FONSECA, 2008). Nesse sentido, os rolês realizados nesses lugares não representariam atos de resistência, ressignificação ou mesmo rebeldia na mesma dimensão que representam nos shoppings.

Diante de tudo que foi discutido, deseja-se enfatizar que o que deveria ser primeiramente discutido e combatido é a segregação social, é a exclusão de determinados grupos sociais do pertencimento simbólico a determinados espaços e práticas. Se não houvesse essa exclusão, o acesso de jovens da periferia aos shoppings não seria algo tão incômodo, ou talvez não ganhasse a dimensão de enfrentamento que vem ganhando até mesmo na própria maneira pela qual esses jovens se comportam nos momentos dos rolês.

Nesse sentido, reitera-se a contribuição do artigo de trazer um posicionamento divergente, entendendo que o periférico tem direito de acesso e de apropriação dos shoppings. Por esse motivo, ao se pensar em possibilidades que têm sido discutidas a respeito da ampliação, pelo poder público, dos lugares de lazer dentro das periferias, essa seria uma prática legítima no que se refere ao acesso ao lazer por parte dos vários grupos sociais. O que seria importante, ainda é a inclusão de políticas de disponibilização de espaços de lazer nas periferias sem distinção de nível no que se refere aos espaços públicos de lazer disponíveis nos espaços e bairros mais valorizados das cidades. 
No entanto, é importante ressaltar que esta inclusão, ao ser tratada como uma alternativa para conter os rolês, acaba reiterando como efeito secundário a segregação que sempre reinou nesses espaços. Reitera também a segregação urbana, ao buscar manter esses grupos em seus lugares de pertença simbólica. E poderia ser uma alternativa eficaz em termos ideológicos por buscar a contenção dos rolês não pela via da força, mas por uma prática simbólica de manutenção do estado de coisas atual.

\section{Considerações finais}

O objetivo deste ensaio foi trazer um panorama sobre o que vinham discutindo os estudos que consideravam os shoppings espaços representativos da segregação social e urbana, para contextualizar a discussão que se tinha como principal objetivo: refletir sobre o que o fenômeno dos rolês (1) agrega e em que (2) desafia esses estudos.

$\mathrm{O}$ fenômeno agrega (a) elementos empíricos que reforçam o shopping como espaço que simboliza a segregação social e urbana; (b) elementos empíricos para a caracterização dos shoppings como sendo espaços vinculados a dinâmicas de significação, ressignificação e resistência; (c) contribuições para as reflexões de que o acesso ao consumo por parte de grupos sociais desfavorecidos não garante a eliminação de outros processos de exclusão social; e (d) novas possibilidades e necessidades de interfaces entre vários campos de conhecimento para a sua compreensão.

Considera-se que o fenômeno demanda (a) um tratamento analítico mais aprofundado da relação que estabelece com a dimensão do consumo; e (b) um desafio relativo à posição do pesquisador diante do objeto e/ou sujeito que estuda, ao poder considerar o rolê como uma prática política sem que os próprios jovens da periferia necessariamente apontem o caráter político de suas ações. Sugere-se ainda que podem ser feitos aprofundamentos na associação do fenômeno do rolê à dimensão do consumo, fazendo com que perspectivas críticas acerca da sociedade de consumo sejam resgatadas e avançadas, ao mesmo tempo em que se fortaleça um olhar crítico acerca do espaço dos shoppings.

A apropriação do shopping pelo periférico e a inclusão desse grupo pelo consumo não solucionariam o fato de que o acesso aos bens funciona atualmente como uma forma de classificar as pessoas. Os jovens da periferia enfrentam outros desafios (como a violência e a falta de acesso a equipamentos públicos). Assim, não se trata de simplificar o contexto em que se inserem ou as possíveis soluções.

Dentro da lógica do "compro, logo existo", esses jovens ganham notoriedade porque incomodam, mas não porque passam a "existir" de fato no que se refere ao acesso legitimado a outros sinais simbólicos de 
distinção social. Não passam a "existir" como aqueles que podem ultrapassar a esfera do consumo e serem considerados sujeitos pertencentes a todos os espaços e práticas a eles vinculados. Trata-se do surgimento de um fenômeno que provoca o transbordamento de estruturas sociais desiguais, trazendo à tona, entre outros aspectos, a constituição histórica de espaços segregados, tanto no que se refere às práticas concretas envolvidas nesses espaços, quanto à constituição simbólica dos mesmos.

Defende-se aqui que a dimensão da segregação seja vinculada aos estudos sobre os rolês, mesmo se esses fenômenos forem associados à dimensão do consumo. Afinal, eles só geraram repercussão por se referirem a jovens da periferia ocupando espaços que simbolicamente não lhes pertencem, desestruturando e ameaçando sinais da distinção de outros grupos sociais.

Chamou-se atenção não apenas para a construção de características peculiares para os shopping centers, como as que os fazem assumir um papel de cidades fictícias, mas sobretudo para a reprodução simbólica, nesses espaços, de dinâmicas históricas e mais amplas de distinção social e consequente distanciamento simbólico de grupos sociais (como nos mostra Bourdieu (1983) ao discutir as distinções simbólicas entre a burguesia e a pequena burguesia).

Por fim, apresentaram-se aqui diversas perspectivas teóricas, dando destaque para a perspectiva da segregação social e urbana; de processos históricos de distinção simbólica entre grupos sociais; de dinâmicas de significação, ressignificação e resistência, considerando poder e resistência duas dimensões relacionais; e do surgimento da sociedade de consumo e a crítica à mesma.

Para fazê-lo, foram utilizados autores com posicionamentos epistemológicos distintos, fazendo uma espécie de bricolagem de perspectivas. Entendeu-seque essa bricolagem se fez necessária diante da complexidade e caráter recente do fenômeno analisado. Essas duas características (complexidade e proximidade temporal do fenômeno) impedem, dentro dos limites deste ensaio, a eleição de uma perspectiva mais adequada para lidar com o mesmo, até porque essa não é a pretensão neste artigo.

O que se objetivou (e subjetivou) foi um passeio (um rolê) por um esforço de concatenação de ideias que contribuísse para o estudo dos shoppings como espaços de segregação de maneira associada ao passeio dos jovens da periferia por esses espaços.

\section{Referências}


AGOSTINI, L. A proibição de entrada de pessoas em shopping centers. Corrêa Garcia Agostini Advogados Associados, seção Artigos, dez. 2012.

ALVES, L. A. Reestruturação urbana e criação de novas centralidades: considerações sobre os shoppings centers. Caminhos de Geografia, Uberlândia, v.12, n. 37, p. 171-184, 2011.

ANDRADE, L. M. O shopping center como figura paradigmática do discurso colonial: racismo e poder na América Latina. Sociedade e Cultura, v. 15, n. 1, p. 217-230, 2012.

; FONSECA, M. L. P. Uberlândia: a dinâmica do espaço público e a segregação social. In: Seminário de Iniciação Científica, 12, 2008. Uberlândia. Anais... Uberlândia: Universidade Federal de Uberlândia, 2008.

ANDRADE, L. T. Segregação socioespacial na vida cotidiana: o caso dos condomínios fechados. In: Encontro Anual da Anpocs, 26. Caxambu. Anais... São Paulo: ANPOCS, 2002.

; JAYME, J. G.; ALMEIDA, R. C. Espaços públicos: novas sociabilidades, novos controles. Cadernos Metrópole, v. 21, p. 131-153, 2009. .

ANDRADE, M. T. M. O shopping center na sociedade globalizada e sua complexidade. Dissertação (Mestrado) - Programa de Pós-Graduação em Geografia, Universidade Federal do Rio Grande do Sul, Porto Alegre, 2007, $221 \mathrm{f}$.

BENJAMIN, W. Passagens. Belo Horizonte, São Paulo: UFMG, 2006. Sociologia. São Paulo: Ática, 1985.

BOURDIEU, P. Gostos de classe e estilos de vida. In: Ortiz, R. (Org.). Pierre Bourdieu: sociologia. São Paulo: Ática, 1983.

O poder simbólico. 11. ed. Rio de Janeiro: Bertrand Brasil, 2007. Razões práticas: sobre a teoria da ação. Campinas: Papirus, 1996. What makes a social class? On the theoretical and practical existence of groups. Berkeley Journal of Sociology, v. 32, p. 1-17, 1987.

CASTILHOS, R. B. Subindo o morro: consumo, posição social e distinção entre famílias de classes populares. Dissertação. 2007. 205 f. Programa de 
Juliana Cristina Teixeira | Amon Narciso de Barros

Pós-Graduação em Administração, Universidade Federal do Rio Grande do Sul, Porto Alegre, 2007.

DUHAU, E. Las metrópolis latinoamericanas en el siglo XXI: de la modernidad inclonclusa a la crisis del espacio público. Cadernos IPPUR, Rio de Janeiro, v. 15, n. 1, jan./jun. 2001.

FOUCAULT, M. Microfísica do poder. Rio de Janeiro: Graal, 1992.

GREGOLIN, M. D. R. Discurso e mídia: a cultura do espetáculo. São Carlos: Claraluz, 2003.

LEITÃO, L. Quando um muro separa e nenhuma ponte une. Cadernos Metrópole, v. 13, p. 229-253, 2005.

MOURA, C. S. S. “No shopping nóis é patrão!": sociabilidade e lazer entre jovens de periferia. 2012. 107f. Dissertação. Programa de Pós-Graduação em Antropologia, Universidade Federal da Bahia, Salvador, Bahia, 2012.

NASCIMENTO, M. C. R. et. al. Com que Cor eu Vou pro Shopping de BH que Você me Convidou?. In: ENCONTRO DA ANPAD - EnANPAD, 37, Rio de Janeiro, 2013. Anais... Rio de Janeiro: ANPAD, 2013.

NEUMAN, C. Marcas de grife têm vergonha de seus clientes mais pobres, diz Data Popular. UOL, 03/02/2014. Disponível em:

<http://economia.uol.com.br/noticias/redacao/2014/02/03/marcas-degrife-tem-vergonha-de-clientes-mais-pobres-diz-data-popular.htm $>$. Acesso em: 15/02/2014.

PADILHA, V. Desafios da crítica imanente do lazer e do consumo a partir do shopping center. ArtCultura, Uberlândia, v. 10, n. 17, p. 103-119, jul./dez. 2008.

Shopping center: a catedral das mercadorias. São Paulo: Boitempo, 2006.

PAIM, E. A.; BUENO, M. F. G. Imagens da Modernidade Capitalista em Walter Benjamin. Cadernos Walter Benjamin, v. 8, p. 1-28, 2012.

POLETTO, I. Rolezinhos: os pobres afrontando sua invisibilidade. Ivo Poletto Blogspot, 20 jan. 2014. Disponível em: <http:/ /ivopoletto.blogspot.com.br/2014/01/rolezinhos-os-pobresafrontando-sua.html. Acesso em: 10 abril.2014. 
OS ROLEZINHOS EM SHOPPING CENTERS: REFLEXÕES SOBRE O QUE AGREGAM E EM

QUE DESAFIAM OS ESTUDOS DOS SHOPPINGS COMO ESPAÇOS DE SEGREGAÇÃO

\section{SOCIAL E URBANA}

Juliana Cristina Teixeira | Amon Narciso de Barros

SCALCO, L. M.; PINHEIRO-MACHADO, R. Os sentidos do real e do falso: o consumo popular em perspectiva etnográfica. Revista de Antropologia, São Paulo, v. 53, n. 1, p. 321-359, 2010.

VEJA. "Só você não me conhece". Revista Veja, São Paulo, v.47, n. 5, 29 jan. 2014a.

Carta ao leitor. Revista Veja, São Paulo, v. 47, n. 5, 29 jan. 2014 b.

VILLAÇA, F. São Paulo: segregação urbana e desigualdade. Estudos Alavancados, v. 25, n. 71, p. 37-58, jan./abr. 2011.

Submetido em: 15/12/2016

Aprovado em: 10/04/2017 